\title{
A Comparative Study of the Chromosomes in 5 Species of Birds from the Genus Aratinga (Psittaciformes: Aves) ${ }^{1}$
}

\author{
Edmundo José de Lucca \\ Departamento de Genética, \\ Instituto Básico de Biologia Médica e Agrícola, \\ Universidade Estadual Paulista "Julio de Mesquita Filho", \\ 18600 Botucatu, SP, Brasil
}

Received February 23, 1983

While many species representing most of the major groups of birds have been karyotyped in recent years, the Psittaciformes belong to the least studied groups of birds. So far, the karyotypes of no more than nine species are known: van Brink (1959), Rothfels et al. (1963) and Ohno et al. (1964) studied the karyotype of Melopsittacus undulatus; Ray-Chaudhuri et al. $(1966,1969)$ described the karyotypes of three species of the genus Psittacula and one of the genus Loriculus; Lucca (1974) showed that Brotogeris sanctithomae had $2 n=72$ chromosomes, while de Boer and Belterman (1980) described the karyotypes of three parrots (Nestor notabilis, Amazona ochrocephala and Psittacus erithacus).

The aim of the present paper is to bring on record the data of 5 Aratinga species, most of which are new to cytology. Possible mechanisms involved in karyotypic evolution in this group are discussed.

\section{Materials and methods}

The following species have been investigated: Aratinga aurea ( 2 males and 2 females); A. auricapilla (2 males); A. cactorum (1 male and 1 female); A. leucophthalmus ( 2 males and 2 females) and $A$. solstitialis ( 2 males).

Chromosome preparations were obtained from colchicinized bone marrow cells by the conventional flame-drying technique (Ford and Hamerton 1956). For Gbands a modification of the techique of Seabright (1971) was used. The technique of Jorge and Benirschke (1977) was used for C-bands.

Relative length and arm ratio were calculated according to Rothfels and Siminovitch (1958). In the chromosome measurements the microchromosomes were always included. Morphometric analysis of the karyotypes was based on five well spread metaphase plates. The system of Levan et al. (1964) was followed for the nomenclature of chromosomes.

\section{Results}

Table 1 shows the values of relative length and arm ratio of the first eight pairs

1 This research was supported by Conselho Nacional de Desenvolvimento Cientifico e Tecnológicao (PIG-III-PROC. No. 40,0499/80). 


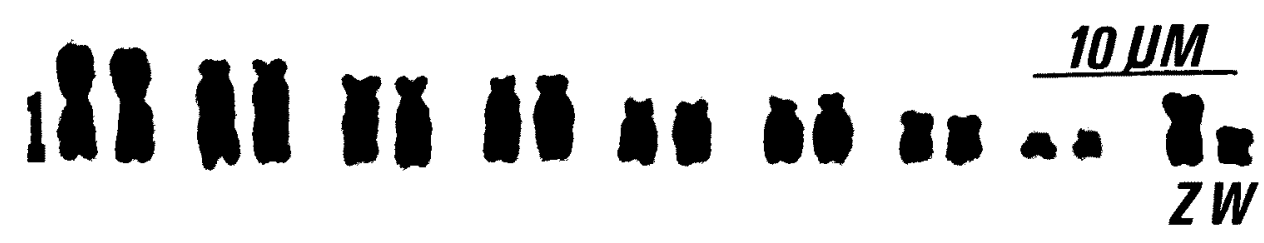

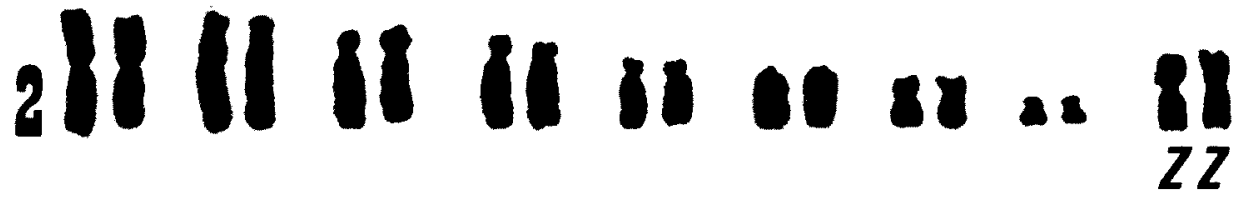

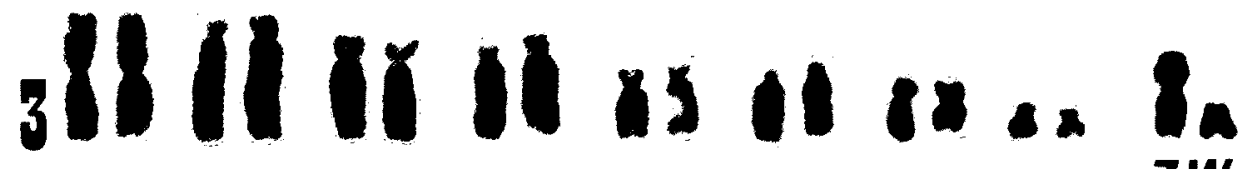

$Z W$

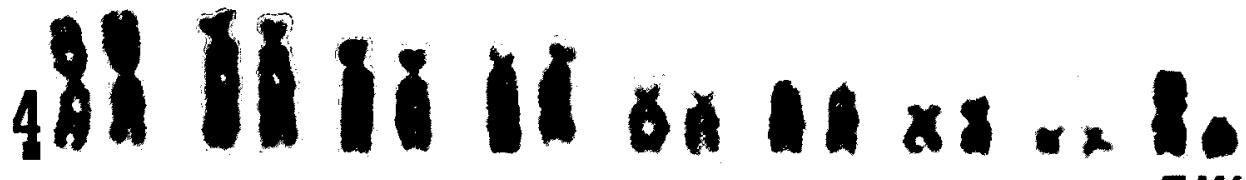

$Z W$

58811010000.68

$Z Z$

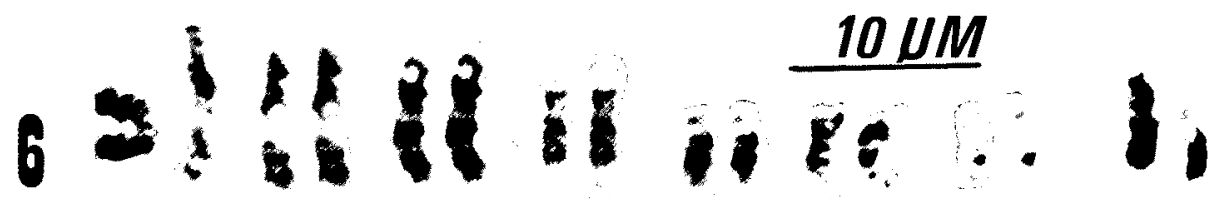

$Z W$

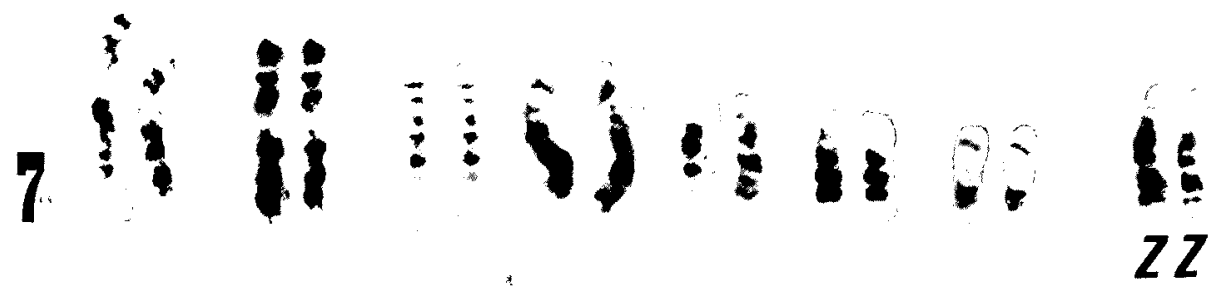

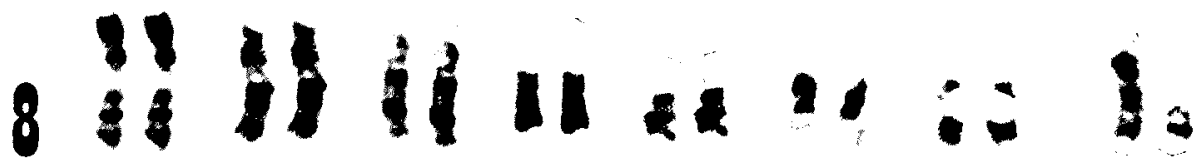

$Z w$ 
of autosomes and sex-chromosomes of the species investigated.

The somatic macrochromosomes obtained for each species are presented in Figures 1 to 5. The G-band karyotypes of A. aurea, A. cactorum and A. leucophthalmus are presented in Figures 6, 7 and 8 respectively. The C-band (constitutive

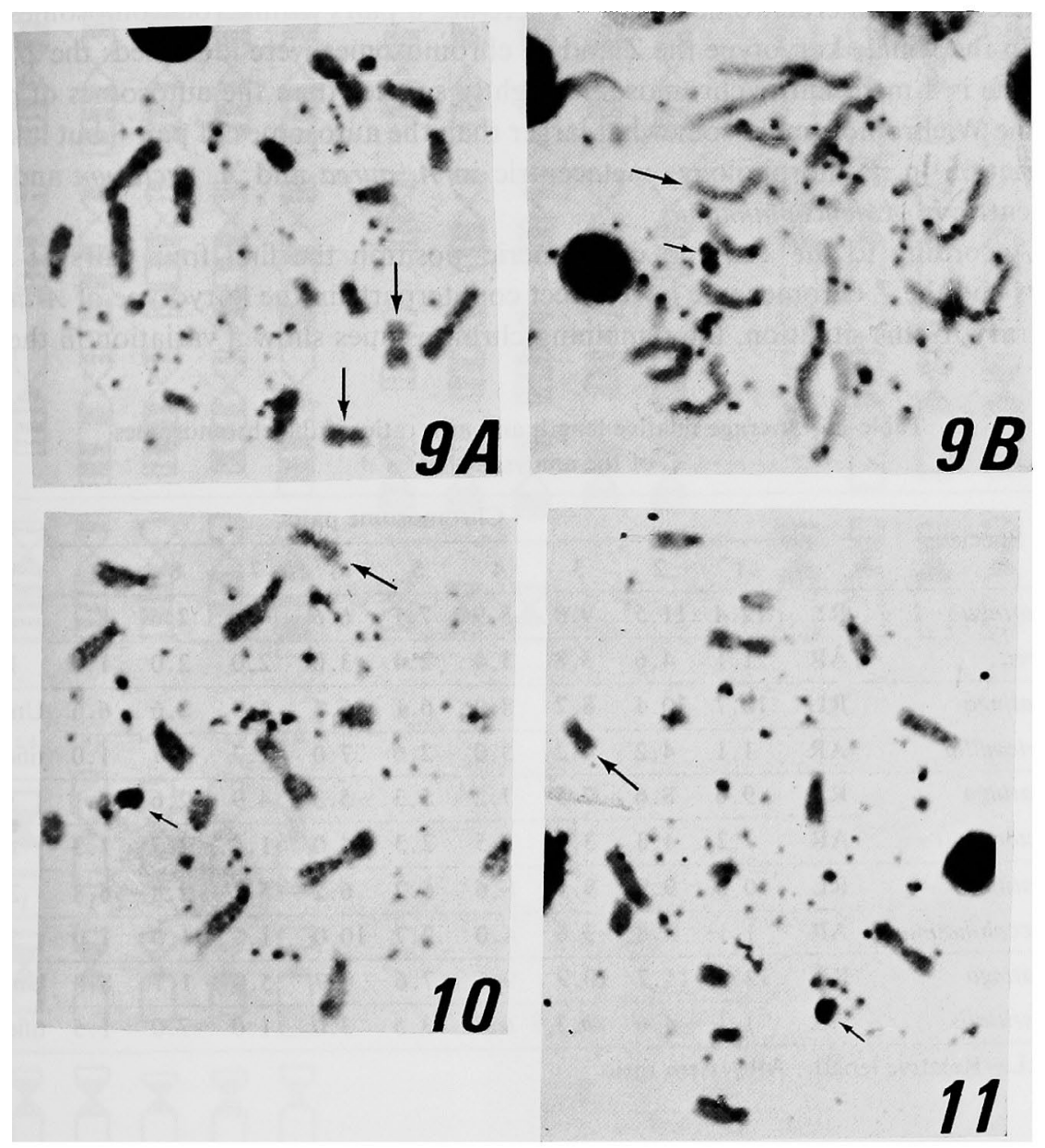

Figs. 9-11. 9, metaphase plates of Aratinga aurea. A, heterochromatin stain (C-bands) of a male (arrow: $Z$ chromosomes); B, metaphase cell of a female Aratinga aurea showing the heterochromatic $W$ chromosome (small arrow). Large arrow shows the $Z$ chromosome. 10, heterochromatin stain (C-bands) of a female Aratinga cactorum (small arrow: W chromosome; large arrow: $\mathrm{Z}$ chromosome). 11, C-bands of a female Aratinga leucophthalmus showing the heterochromatic $\mathrm{W}$ chromosome (small arrow). Large arrow shows the $\mathrm{Z}$ chromosome.

Figs. 1-8. 1, the somatic macrochromosomes of a female Aratinga aurea $(2 n=70) . \quad 2$, the somatic macrochromosomes of a male Aratinga auricapilla $(2 \mathrm{n}=70)$. 3 , the somatic macrochromosomes of a female Aratinga cactorum $(2 \mathrm{n}=70) . \quad 4$, the somatic macrochromosomes of a female Aratinga leucophthalmus $(2 \mathrm{n}=70) . \quad 5$, the somatic macrochromosomes of a male Aratinga solstitialis $(2 \mathrm{n}=70) . \quad 6$, partial G-banded karyotype of a female Aratinga aurea. 7, partial G-banded karyotype of a male Aratinga cactorum. 8, partial G-banded karyotype of a female Aratinga 
heterochromatin) karyotypes of $A$. aurea, A. cactorum and A. leucophthalmus are shown in Figures 9,10 and 11 respectively. The schematic representation of the G- and C-banding patterns of the macrochromosomes of the five species examined are shown in Figure 12. It is concluded that the diploid chromosome number in Aratinga is 70 for all the analysed species. There is a very sharp boundary between the macro- and microchromosomes. There are 8 pairs of macrochromosomes.

In the female karyotype the $\mathrm{Z}$ and $\mathrm{W}$ chromosomes were identified: the $\mathrm{Z}$ chromosome is a metacentric chromosome slightly smaller than the autosomes of pair 4 and the $\mathrm{W}$ chromosome is somewhat larger than the autosomes of pair 8 but it shows a variation in its morphology: metacentric in $A$. aurea and $A$. cactorum and subtelocentric in $A$. leucophthalmus.

According to the size and centromeric position the first four pairs of autosomes and the $\mathrm{Z}$ chromosome have direct counterparts in the karyotype of Aratinga. Contrary to this situation, the remaining chromosomes show a variation in the cen-

Table 1. Average relative length and arm ratio of the chromosomes of the analysed species

\begin{tabular}{|c|c|c|c|c|c|c|c|c|c|c|c|}
\hline \multirow{2}{*}{ Species } & \multicolumn{11}{|c|}{ Chromosome pairs } \\
\hline & & 1 & 2 & 3 & 4 & 5 & 6 & 7 & 8 & $\mathrm{Z}$ & W \\
\hline \multirow{2}{*}{$\begin{array}{l}\text { Aratinga } \\
\text { aurea }\end{array}$} & RL & 12.4 & 11.5 & 9.8 & 8.9 & 7.1 & 6.6 & 4.9 & 2.6 & 8.1 & 3.2 \\
\hline & AR & 1.1 & 4.6 & 3.8 & 3.4 & 2.4 & 3.0 & 2.0 & 2.0 & 1.0 & 1.0 \\
\hline \multirow{2}{*}{$\begin{array}{l}\text { Aratinga } \\
\text { auricapilla }\end{array}$} & RL & 10.7 & 10.4 & 8.7 & 8.0 & 6.1 & 5.4 & 4.3 & 2.6 & 6.6 & Uniden- \\
\hline & AR & 1.1 & 4.2 & 4.2 & 3.0 & 2.6 & 7.0 & 1.7 & 1.7 & 1.0 & tified \\
\hline \multirow{2}{*}{$\begin{array}{l}\text { Aratinga } \\
\text { cactorum }\end{array}$} & $R L$ & 9.6 & 8.6 & 7.5 & 7.2 & 5.3 & 5.3 & 4.9 & 2.6 & 6.1 & 3.0 \\
\hline & AR & 1.2 & 4.3 & 3.0 & 3.5 & 2.3 & 4.0 & 1.5 & 2.3 & 1.3 & 1.4 \\
\hline \multirow{2}{*}{$\begin{array}{l}\text { Aratinga } \\
\text { leucophthalmus }\end{array}$} & $\mathrm{RL}$ & 10.2 & 9.9 & 9.1 & 8.6 & 6.2 & 6.2 & 5.2 & 2.8 & 6.8 & 2.8 \\
\hline & AR & 1.1 & 4.8 & 3.6 & 4.0 & 2.7 & 10.0 & 1.3 & 1.0 & 1.0 & 5.0 \\
\hline \multirow{2}{*}{$\begin{array}{l}\text { Aratinga } \\
\text { solstitialis }\end{array}$} & $R L$ & 12.6 & 11.7 & 10.9 & 9.6 & 7.6 & 6.7 & 5.0 & 1.7 & 8.3 & Uniden- \\
\hline & AR & 1.1 & 4.6 & 3.3 & 6.7 & 3.5 & 3.0 & 1.0 & 7.0 & 1.5 & tified \\
\hline
\end{tabular}

tromeric position (Table 1 and Figs. 1 to 5) probably due to pericentric inversions.

Comparison of the G-banding patterns of the chromosomes of these bird species (Figs. 6 to 8 and Fig. 12) demonstrates that the largest pairs of macrochromosomes have similar patterns whereas the $\mathrm{Z}$ chromosome of $A$. aurea is unique.

The C-band positive regions are similar in all species, except that $A$. solstitialis appears to possess less constitutive heterochromatin, whereas $A$. cactorum appears to possess more constitutive heterochromatin. The macrochromosomes possess only a small amount of constitutive heterochromatin near the centromere, whereas the $\mathrm{W}$ chromosome is darkly stained in all the three species showing a distinctively darker region near the centromere. The microchromosomes possess varying amounts of heterochromatin, and some of them possess more C-band materials than the macrochromosomes except the W (Figs. 9 to 11 and Fig. 12). 
In our $A$. cactorum material one chromosome in the 4 th pair showed a distinctive C-band in the short arm (Fig. 13).
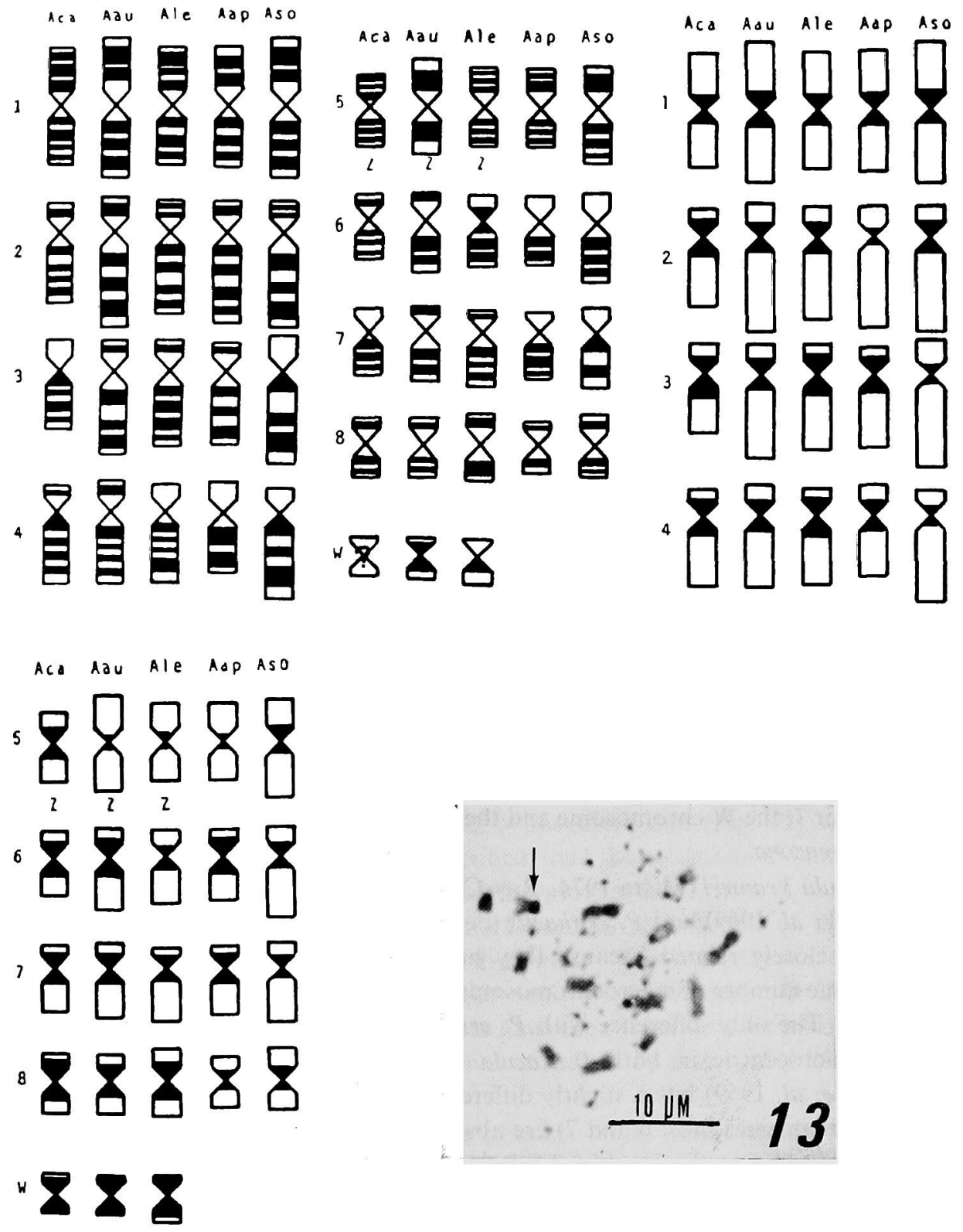

12

Figs. 12-13. 12, schematic representation of the G- and C- banding patterns of the macrochromosomes of Aratinga. Aca: A. cactorum; Aau: A. aurea; Ale: A. leucophthalmus; Aap: A. auricapilla; Aso: A. solstitialis. 13, C-bands of a male Aratinga auricapilla. The arrow shows the heterochromatization of the small arm of a homologous of chromosome 4. 


\section{Discussion}

The order Psittaciformes is known cytologically from the study of nine species belonging to a single family Psittacidae. Three out of these nine worked out species are congeneric and the remaining six belong to different genera.

As indicate above, the karyotypes of Aratinga are very much alike. The only differences concern the morphology of the chromosomes of the 5 th pair in A. solstitialis, 6th pair in $A$. auricapilla and 7th pair which is made up of submetacentrics in $A$. aurea and $A$. auricapilla; in the remaining species the 7 th pair is compared of metacentrics. The 8 th pair of macrochromosomes is represented by submetacentrics in A. aurea, A. auricapilla and A. cactorum, metacentrics in A. leucophthalmus and telocentrics in $A$. solstitialis. The diploid chromosome number of these species is 70 and there is a clear boundary between macro- and microchromosomes. Five of the psittacine karyotypes described so far lack the sharp macro-microchromosome boundary. Loriculus vernalis (Ray-Chaudhury et al. 1969) has a quite distinct karyotype in that it shows only one pair of metacentric chromosomes, all the other elements being telocentric. Brotogeris sanctithomae (Lucca 1974) has a karyotype closely related to that of Loriculus vernalis with $2 n=72$ and the morphology of the chromosomes of this species like in Loriculus, is strikingly different from that of any other species so far described; only the $\mathrm{Z}$ and $\mathrm{W}$ are metacentric chromosomes, all the remaining elements being telocentric. Melopsittacus undulatus (van Brink 1959, Rothfels et al. 1963, Ohno et al. 1964) is shown to have a very distinct karyotype including several pairs of smaller biarmed chromosomes probably evolved from fusions of microchromosomes, which may account for the relatively low diploid number $(2 \mathrm{n}=58)$. Nestor notabilis and Amazona ochrocephala (de Boer and Belterman 1980) show many similarities in spite of the fact that Nestor presents a diploid number of 62 and Amazona, 70. The major differences lie in the structure of the chromosomes of pair 1 , the $\mathrm{W}$ chromosome and the slightly higher number of microchromosomes in Amazona.

Psittacula krameri (Misra 1974, Ray-Chaudhuri et al. 1969), P. alexandri (RayChaudhuri et al. 1969) and P. erithacus (de Boer and Belterman 1980) are assumed to be very closely related because they have almost identical karyotypes. They have the same number of macrochromosomes with a sharp macro-microchromosome boundary. The only difference with $P$. erithacus seems to be that the elements of pair 6 are acrocentric in both Psittacula species. Psittacula cyanocephala (RayChaudhuri et al. 1969) has a slightly different karyotype. In this species large telocentric chromosomes (nos. 6 and 7) are absent, which are replaced by a metacentric one corresponding to the combined relative lengths of nos. 6 and 7 chromosomes in other forms of Psittacula. A similar change has been ascribed to the Robertsonian fusion in three of the four species studied by Ray-Chaudhuri et al. (1969) where two telocentrics are found instead of one metacentric.

The karyotypes of Aratinga show great similarity to those of Psittacula krameri (Ray-Chaudhury et al. 1969, Misra 1974), P. alexandri (Ray-Chaudhuri et al. 1969), $P$. erithacus and Nestor notabilis (de Boer and Belterman 1980). Characteristic features of these species are the large size of chromosomes in pairs 1, 2, 3 and 4. 
The karyotypes of Psittacula krameri, P. alexandri, Amazona ocrocephala, Psittacus erithacus and species of the genus Aratinga are characterized by the subtelocentric autosomes in pairs 2, 3 and 4. Ray-Chaudhuri (1973) however, states that the longest telocentrics of Loriculus vernalis are similar in length to the three pairs of subtelocentrics in Psittacula. The karyotypes of Loriculus vernalis and Brotogeris sanctithomae show great similarity with a predominance of telocentric chromosomes. A series of pericentric inversions are the only explanation for the derivation of the karyotype of these species. The $\mathrm{Z}$ chromosome is also telocentric in Loriculus while it is metacentric in all the remaining species of Psittaciformes.

The banding patterns of bird chromosomes have revealed a surprising similarity for the three or four largest chromosomes (Takagi and Sasaki 1974, Stock et al. 1974, Stock and Mengden 1975, Ryttman et al. 1979, Ryttman and Tegelström 1981). This fact is obvious for the largest chromosomes in Aratinga. Therefore, it is not surprising that the karyotypes including the G- and C-bands of the closely related species studied here are found to be neary identical.

The C-band positive heterochromatin has hitherto been studied in only a limited number of avian species (Stefos and Arrighi 1971, Comings and Mattoccia 1972, Stock et al. 1974, Au et al. 1975, Raman et al. 1978, Ryttman et al. 1979, Carlenius et al. 1981). It has been observed that 1) although the $\mathrm{W}$ is the only heterochromatic chromosome in the parakeet, pheasant, duck and quail, in the dove, pigeon, Japanese quail, bald eagle, chicken, myna, jungle babble and duck, the centromeres of several microchromosomes are also $\mathrm{C}$-band positive, 2) the centromeres of the macrochromosomes are either devoid of the $\mathrm{C}$-band or possess it in only a trace.

The C-band positive regions are similar in all the five species, but Aratinga solstitialis appears to possess less constitutive heterochromatin whereas $A$. cactorum appears to possess more.

As mentioned elsewhere, the 4th pair of chromosomes in $A$. cactorum are heteromorphic in terms of the C-band pattern of the short arm (Fig. 13). Stock et al. (1974) and Carlenius et al. (1981) described that the telomeric C-bands of the Z chromosome in Gallus domesticus are polymorphic in size.

In some orders (Charadriiformes and Ciconiiformes) there is an obvious tendency to reduction in the number of chromosomes. This tendency is clearly expressed in the species so far analysed in the order Psittaciformes. In Melopsittacus undulatus the smallest macrochromosomes have been created by Robertsonian translocation between large microchromosomes as judged by their metacentric morphology.

Ansari and Kaul (1979) suggested a possible occurrence of microchromosomal addition to the telocentric chromosome 3 in Oriolus xanthornus. Stock et al. (1974) investigated the G-banded karyotype of the pigeon and the dove and suggested that the interspecific differences in karyotypes result from the fusion of four pairs of microchromosomes of the pigeon to form two pairs of metacentric macrochromosomes in the dove. In the order Psittaciformes, Ray-Chaudhuri et al. (1969) state that in Psittacula cyanocephala a single translocation of the Robertsonian type is the most simple explanation of the derivation of a large metacentric chromosomes. Lucca (unpublished) found a translocation involving chromosomes 1 and 6 in Forpus 
xanthopterygius.

A greater amount of constitutive heterochromatin was found in Psittaciformes compared to Columbiformes (Lucca 1980). He suggested that a part of the heterochromatin which was added to the macrochromosomes from microchromsomes was insertionally translocated into the pericentromeric region.

\section{Summary}

Karyotypes were compared in 5 species of Aratinga (Psittaciformes). The macrochromosomes of each species were analysed by the conventional Giemsa staining, with cytobiometry, and G- and C-banding. All the species showed $2 \mathrm{n}=70$ chromosomes. These karyotypic data are compared to those in the literature on nine other parrot species. The reduced chromosome number in Aratinga was attributed to the fusion of microchromosomes into macrochromosomes.

\section{Acknowledgments}

The author expresses his gratituted to the Conselho Nacional de Desenvolvimento Científico e Tecnológico $(\mathrm{CNPq})$ for the financial support (Pig III-Proc. No. 40.0499/80),

\section{References}

Ansari, H. A. and Kaul, D. 1979. Somatic chromosomes of black-headed oriole Oriolus xanthornus (Linn.): a probable case of translocation heterozygosity. Experientia 35: 740-741.

$\mathrm{Au}, \mathrm{W}$, Fechheimer, N. S. and Soukup, S. 1975. Identification of the sex chromosomes in the bald eagle. Can. J. Genet. Cytol. 17: 187-191.

Boer, L. E. M. de and Belterman, R. H. R. 1980. The somatic chromosomes of three parrots: the kea (Nestor notabilis), the yellow-headed parrot (Amazona ochrocephala) and the grey parrot (Psittacus erithacus). Acta Zoologica et Pathologica antiverpiensia 75: 9-18.

Brink, J. M. van 1959. L'expression morphologique de la digamétie chez les Sauropsidés et les Monotremés. Chromosoma 10: 1-72.

Carlenius, C., Ryttman, H., Tegelström, H. and Jansson, H. 1981. R-, G- and C- banded chromosomes in the domestic fowl (Gallus domesticus), Hereditas 94: 61-66.

Comings, D. E. and Mattoccia, E. 1972. DNA of mammalian and avian heterochromatin. Exptl. Cell Res. 71 : 113-131.

Ford, C. E, and Hamerton, L. T. L. 1956. A colchicine hypotonic citrate squash sequence for mammalian chromosome. Stain Tech, 31: 247-251.

Jorge, W. and Benirschke, K. 1977. Centromeric heterochromatin and G-banding of the red brocket deer, Mazama americana temama (Cervoidia, Artiodactyla) with a probable nonRobertsonian translocation. Cytologia 42: 711-721.

Levan, A., Fredga, K. and Souberg, A. A. 1964. Nomenclature for centromeric position on chromosomes. Hereditas 52: 201-220.

Lucca, E. J. de 1974. Cariótipos de 8 espécies de aves. Rev. Brasil. Biol. 34: 387-392.

- 1980. Mecanismos de evolução cromosssômica em Columbiformes e Psittaciformes (Aves). Tese de Livre-Docência. Instituto Básico de Biologia Médica e Agrícola. Universidade Estadual Paulista, Botucatu, SP. 128 p.

Misra, N. 1974. Studies on the chromosomes of birds. Ph. D. Thesis, University of Allahabad, India. 
Ohno, S., Stenius, C., Christian, L. C., Beçak. W. and Beçak, M. L. 1964. Chromosomal uniformity in the avian sub-class Carinatae. Chromosoma 15: 280-288.

Pinto, O. M. O. 1978. Novo catálogo das aves do Brasil. $1^{a}$ Parte. Empresa Gráfica da Revista dos Tribunais S. A., São Paulo, 446 p.

Raman, R., Jacob, M. and Sharma, T. 1978. Heterogeneity in distribution of constitutive heterochromatin in four species of birds. Genetica 48: 61-65.

Ray-Chaudhuri, S. P., Ray-Chaudhuri, R. and Sharma, T. 1966. The W-chromosome in females of two Indian species of birds. Chromosoma 20: 151-154.

Ray-Chaudhuri, R. 1973. Cytotaxonomy and chromosome evolution on birds. In: Cytotaxonomy and Vertebrate Evolution. Cambridge University Press. London, p. 425-483.

-, Sharma, T. and Ray-Chaudhuri, S. P. 1969. A comparative study of the chromosomes of birds. Chromosoma 26: 148-168.

Rothfels, K. H. and Siminovitch, L. 1958. The chromosome complement of rhesus monkey (Macaca mulata) determined in kidney cell cultivated in vitro. Chromosoma 9: 163-175.

Rothfels, D. H., Aspden, M. and Mollison, M. 1964. The W-chromosome of the budgeriger, Melopsittacus undulatus. Chromosoma 14: 459-467.

Ryttman, H. and Tegelström, H. 1981. G-banded karyotypes of three Galliformes species, domestic fowl (Gallus domesticus), quail (Coturnix coturnix japonica) and turkey (Meleagris gallopavo). Hereditas 94: 165-170.

_, - and Jansson, H. 1979. G- and C-banding in four related Larus species (Aves). Hereditas 91: $143-148$.

Seabright, M. 1971. A rapid banding technique for human chromosomes. Lancet 2: 971-972.

Stefos, K. and Arrighi, F. E. 1971. Heterochromatin nature of the W chromosome in birds. Exptl. Cell Res. 83: 9-14.

Stock, A. D. and Mengden, G. A. 1975. Chromosome banding pattern conservatism in birds and nonhomology of chromosome banding patterns between birds, turtles, snakes and amphibians. Chromosoma 50: 67-77.

-, Arrighi, F. E. and Stefos, K. 1974. Chromosome homology in birds: banding patterns of the chromosomes of the domestic chicken, ring necked dove and domestic pigeon. Cytogenet. Cell Genet. 13 : $410-418$.

Takagi, N. and Sasaki, M. 1974. A phylogenetic study of bird karyotypes. Chromosoma 46: 91-120. 